\title{
The structure of early counting competence
}

\author{
ROBERTA A. FERRARA and TERENCE TURNER \\ University of Kentucky, Lexington, Kentucky
}

(Robert F. Lorch, Jr., Sponsor)

\begin{abstract}
This research examined the structure underlying preschoolers' knowledge of counting. Factor analysis indicated that three first-order factors and one higher order factor accounted for $57 \%$ of the variance in performance on a variety of counting tasks. The results are consistent with a model of early number competence that has three basic components: (1) a verbal component involving knowledge of the conventional number-word sequence, (2) an action component involving knowledge of tagging behaviors in object-counting procedures, and (3) a contextual component involving knowledge of the basic goals and uses of counting.
\end{abstract}

Over the past two decades, there has been a great deal of research on early number competence (for reviews, see, e.g., Fuson \& Hall, 1983; Gelman \& Gallistel, 1978; Siegler $\&$ Robinson, 1982), yet there has been relatively little attention paid to the structure that underlies this competence. Various number concepts and procedures have been examined in isolation, with scant regard for how this conceptual and procedural knowledge might be organized in the young child's mind. Researchers who assume a nativist position have tended to study various aspects of object counting (e.g., Gelman \& Meck, 1983). Others who lean toward a learning position have focused more on verbal counting procedures in the absence of actual objects (e.g., Fuson \& Hall, 1983). The present article investigates how these different types of knowledge relate to one another.

It has been claimed that student's knowledge of counting has a substantial impact on their responsiveness to beginning mathematics instruction (e.g., Baroody \& Ginsburg, 1982). Perhaps the earliest mathematical strategy commonly exhibited by children is a physical modeling procedure (Carpenter \& Moser, 1982). That is, many young children frequently attempt to act out or model addition problems

This research was supported by PHS Grants HD-05951 and HD-15808 awarded by the National Institute of Child Health and Human Development. Thanks are extended to the directors, teachers, children, and parents associated with Champaign-Urbana Day Care Center, Children's Center Day Care, Early Learning Center, First United Methodist Child Care Center, Gerber Children's Center, the ICBD Children's Learning Center, Kinder-Care Learning Center, Montessori School of ChampaignUrbana, The Next Generation, and the University of Illinois Child Development Laboratory, and to all those associated with the Bement Grade School, in particular to Superintendent Dan Mash, Joyce Kaufman, and Barbara Waters. For assistance with data collection and analysis, we extend additional thanks to Becky Davison and Linda Purcell. The studies reported represent a portion of Roberta Ferrara's doctoral research conducted at the University of Illinois at Urbana-Champaign. She is indebted to Ann Brown, her academic advisor and the director of her thesis research, as well as to the rest of her committee members: Rence Baillargeon, Joseph Campione, Robert Davis, Lawrence Jones, and Robert Reeve. Correspondence should be addressed to T. Turner, Department of Psychology, Kastle Hall, University of Kentucky, Lexington, KY 40506-0044. by making sets of fingers or objects equal in size to the addends, and then counting all of the objects in the combined superset. The purpose of the present study was to assess counting knowledge and skills that might be considered prerequisites for learning a physical modeling strategy and to determine the structure that underlies this knowledge.

Perhaps the most obvious type of knowledge needed to implement a physical modeling procedure is knowledge of the number-word sequence up through the number corresponding to the sum. Therefore, a simple rote counting task (i.e., "count as high as you can") was included in the assessment to determine the length of the children's conventional number-word sequence. As further indications of the automaticity of this sequence and the strength of associations between numbers in the sequence, the children's abilities to count on and count backward from certain numbers were assessed. According to Fuson and her colleagues (e.g., Fuson, 1982; Fuson \& Hall, 1983), these abilities also reflect more advanced conceptions of the number sequence than that indicated by counting forward from one.

Aside from such basic number sequence knowledge, a physical modeling procedure requires the ability to count objects, which according to Gelman and Gallistel (1978) involves the application and coordination of at least three principles: (1) the one-to-one principle that every object in an array must be associated with one and only one unique tag, (2) the stable-order principle that counting tags must be stated in the same order across counts, and (3) the cardinal principle that the last tag in a count sequence represents the numerosity of the array of objects. (The word tag has been used here, rather than the term number-word, because knowledge of these principles is typically examined independently of knowledge of the conventional number word sequence, and occasionally very young children do not use number words exclusively while counting.) Use of the three "how-to-count" principles was assessed in the context of counting linear arrays of objects. The methods were adapted from the work of Gelman and others (e.g., Baroody \& Price, 1983; Gelman, 1980; Gelman \& Gallistel, 1978; Gelman \& Meck, 1983). 
Additional tasks were included to assess further skill and flexibility in counting sets: (1) a task to examine knowledge of the order-irrelevance principle (Gelman \& Gallistel, 1978) that items in an array may be tagged in any order as long as the other counting principles are not violated, (2) a task in which spatially separated subsets were counted "altogether" as an indication of knowledge of the concept of superset, and (3) a task in which random arrays, rather than linear ones, were counted in order to assess more advanced application of the one-to-one principle (since random arrays require more sophisticated skills for partitioning counted from uncounted objects). Although these three additional kinds of abilities were not seen as absolutely essential to the acquisition of the physical modeling procedure, they were examined here because it was thought that possessing these abilities might reduce difficulties in mastering the strategy.

All of the object-counting tasks mentioned above involve arrays of objects presented by the experimenter. Physical modeling, however, involves the generation of a certain number of objects by the child. This requires the child to maintain in working memory the prespecified number while counting out the objects and to compare continually the current number being counted with the prespecified number. It also requires that the child understand the utility of counting in achieving the goal of accurate set formation. Thus, this subprocedure was examined directly by requesting that the child make sets of various sizes.

Finally, the child's knowledge of written numerals was also assessed, because the use of numerals as notational devices could alleviate the demands placed upon working memory by physical modeling.

There are thus several early number abilities that would be expected to facilitate the acquisition of a physical modeling strategy. These abilities have previously been investigated in isolation, but not in concert. The present study examined their underlying factor analytic structure.

\footnotetext{
Method

Subjects. The subjects were 63 children from five daycare centers and nursery schools in a small city in the Midwestern United States. Ages ranged from 3 years 6 months to 5 years 3 months $(M=4$ years 6 months, $S D=5$ months). There were 31 boys and 32 girls.

Materials and Procedure. Each child was tested individually. Two sessions, each 15-30 min in length, were required to complete the testing of each child. At the beginning of the first session, the child was asked to help the experimenter teach a small male Cabbage Patch doll how to count. This pretense was used in order to set the tasks within a game-like context that would be motivating for preschoolers. The tasks were then presented to the child using a standardized set of instructions.

Eleven subtests were administered across the two sessions. These subtests were arranged in different orders according to a Latin-square design. These orders of presentation were assigned to the children in a rotating sequence (i.e., the first child received Order 1 , the second child got Order 2, and so on). The subtests were briefly described in the introduction of this paper and are listed here (details of procedures and tests can be found in Ferrara, 1987): (1) rote counting (length of conventional number sequence when asked to "count as high as you can"); (2) counting on (from numbers other than 1 , i.e., starting a count with $4,6,9,12$, and 20); (3) counting backward (from 4, 6, 9, 12, and 20 to 1); (4) numerals (recognition of the written numerals $4,6,9,12$, and 20). For the following tests, the subject was presented with a number of blocks: (5) counting linear arrays of blocks-the children were presented with
}

five homogeneous arrays of blocks glued in linear arrangements to fiberboard. The arrays varied in numerosity; thus, 4 blocks were presented first, followed by 6 , then 9 , then 12 , and finally 20 blocks. The spacing of blocks remained constant across numerosities. In one task, each subject was asked to count the number of blocks and given three separate scores (a, b, and c below). In a separate task, the child was asked to start counting with a specific block in the middle of a row, yielding an orderirrelevance measure ( $\mathrm{d}$ below): (a) one-to-one correspondence between numbers and objects counted, (b) stable order of numbers across countsthe stability of order was judged by comparing the order for one numerosity (e.g., 4) with that of the next highest (i.e., 6; note that only four such comparisons could be made with the five numerosities), (c) cardinality ('How many?'), (d) order irrelevance of tagging; (6) superset concept (the counting of spatially separated arrays of blocks: "How many altogether?'); (7) counting random arrays of blocks (the blocks were randomly scattered over the fiberboard, instead of being arranged in linear arrays); (8) making sets of blocks (generating specified numbers of objects i.e., selecting from a box of blocks $4,6,9,12$, and 20 blocks).

Numerosity was varied within all tasks except rote counting and numerals. The five numerosities were always $4,6,9,12$, and 20 , presented in that order. For example, in the counting-on task, each child was asked to count starting with 4 , then to count starting with 6 , and so on, to yield five separate measures of counting-on skill. For tasks 5-7, a child could receive credit in spite of deviations from the conventional number word sequence, as long as he or she used a particular word sequence (e.g., " $1,2,4,5, \ldots$ ') consistently in the task.

\section{Results and Discussion}

The measures of counting competence were highly reliable. Interobserver agreement was $93.7 \%(\mathrm{kappa}=.86)$. In addition, Spearman-Brown split-half coefficients of reliability ranged from .79 to .97 for all of the tasks except one (it was .52 for the random-arrays task).

The means of the 11 subscores, and their intercorrelations, are shown in Table 1. In order to investigate the structure underlying the measures, the total scores for each task were submitted to a maximum likelihood factor analysis. Three factors had eigenvalues greater than 1.0, and together they accounted for $57 \%$ of the variance. When these three factors were subjected to an oblique rotation (direct quartimin), a relatively clear structure emerged, as indicated in Table 2.

The first factor explained nearly a third of the variance (29\%) and was defined by four subtests: counting backward, rote counting, counting on, and numeral recognition. Factor 1 appears to measure primarily the children's knowledge of the conventional number-word sequence, and it will be referred to as the verbal component of counting, because it reflects mainly knowledge of what one says when counting.

A second factor accounted for an additional $16 \%$ of the variance in overall performance. Subscores for cardinality, stable order, and the superset concept loaded mainly on this factor. The making-sets subscore also loaded on this factor (with small loadings on the other factors as well). Factor 2 seems to reflect knowledge related to the contexts in which counting occurs, in determining the sizes of sets and supersets, in making sets of specific sizes, and so on. It will thus be referred to as the contextual component of counting. (One might have expected the stable-order subscore to load instead on the verbal factor. However, the understanding that number words must be stated in a stable order is, of course, different from the understanding that 
Table 1

Intercorrelation Matrix and Means for the 11 Counting Subscores

\begin{tabular}{lrllllllllll}
\hline \multicolumn{1}{c}{ Subscore } & Mean & RC & CO & CB & OO & SO & CA & OI & SS & RA & MS \\
\hline Rote Counting & 30.41 & & & & & & & & & \\
Counting On & 2.68 & $.51^{*}$ & & & & & & & & \\
Counting Backward & 1.54 & $.68^{*}$ & $.67^{*}$ & & & & & & & \\
One to One & 4.25 & .26 & $.33^{*}$ & $.37^{*}$ & & & & & & \\
Stable Order & 3.84 & .19 & .26 & .24 & .04 & & & & & \\
Cardinality & 4.27 & .26 & $.39^{*}$ & .28 & .18 & $.56^{*}$ & & & & \\
Order Irrelevance & 4.73 & .15 & .23 & .24 & $.43^{*}$ & .10 & .15 & & & \\
Superset & 4.84 & .15 & $.30^{*}$ & .22 & .08 & $.51^{*}$ & .28 & .15 & & \\
Random Arrays & 2.84 & $.34^{*}$ & $.41^{*}$ & $.50^{*}$ & $.51^{*}$ & $.31^{*}$ & $.42^{*}$ & .24 & .21 & \\
Making Sets & 3.32 & $.48^{*}$ & $.53^{*}$ & $.56^{*}$ & $.45^{*}$ & $.43^{*}$ & $.64^{*}$ & .25 & $.32^{*}$ & $.59^{*}$ & \\
Numerals & 3.16 & $.40^{*}$ & $.60^{*}$ & $.63^{*}$ & $.37^{*}$ & $.39^{*}$ & $.43^{*}$ & .17 & $.32^{*}$ & $.47^{*}$ & $.57^{*}$ \\
\hline
\end{tabular}

Note $-N=63$. Total score for rote counting was the highest number said in conventional sequence. Total score for all other subtests involved one point for each of the five numerosities responded to appropriately. Thus, the maximum total score was 5.0 for every subtest, except rote counting (no maximum; observed range was 8-150+; median was $19)$ and stable order $($ maximum $=4.0) .{ }^{*} p<.01$.

they must be stated in a conventional order. Stability of order is relevant to demands of internal consistency, whereas conventionality is essential to achieve external consistency.) The third factor explained a further $12 \%$ of the variance and was defined primarily by demonstration of the one-to-one principle. The order-irrelevance and random-arrays subscores also showed modest loadings on Factor 3 (although the latter loaded on the other factors as well). This third factor appears to involve performance aspects of object counting, such as the coordination of number words with tagging gestures, the partitioning of tagged objects from untagged ones, and flexibility in the order of tagging. Thus, Factor 3 will be referred to as the action component of counting.

The intercorrelations among the rotated counting factors ranged from .32 to .52 , which suggested the existence of a higher order or general factor for early counting ability. In order to investigate this possibility, a maximum likelihood confirmatory factor analysis was conducted using LISREL (Jöreskog \& Sörbom, 1984). The first model tested had three first-order factors and one higher level factor on which each lower level factor loaded. It also specified that each subtest loaded on only one first-order factor. This

Table 2

Factor Loadings of the 11 Counting Subscores

\begin{tabular}{lccc}
\hline & \multicolumn{3}{c}{ Factor } \\
\cline { 2 - 4 } \multicolumn{1}{c}{ Subscore } & 1 & 2 & 3 \\
Verbal & Contextual & Action \\
\hline Counting Backward & $1.00^{*}$ & -0.13 & -0.01 \\
Rote Counting & $0.72^{*}$ & -0.02 & -0.03 \\
Counting On & $0.60^{*}$ & 0.17 & 0.06 \\
Numerals & $0.46^{*}$ & 0.28 & 0.14 \\
Cardinality & -0.09 & $0.85^{*}$ & 0.06 \\
Stable Order & -0.02 & $0.73^{*}$ & -0.09 \\
Superset & 0.06 & $0.44^{*}$ & -0.02 \\
Making Sets & 0.22 & $0.55^{*}$ & $0.27^{*}$ \\
One to One & -0.08 & -0.11 & $1.00^{*}$ \\
Order Irrelevance & 0.04 & 0.02 & $0.42^{*}$ \\
Random Arrays & 0.21 & 0.28 & $0.38^{*}$ \\
\hline
\end{tabular}

Note $-N=63$. The starred (*) loadings are those that were free to vary in the final LISREL analysis (except for the one loading per factor that was set to 1.0 to scale the factor), and the unstarred are those that were set equal to zero. model fitted the data reasonably well $\left[x^{2}(42, N=63)=\right.$ $52.99, p=.12$ ]. We also tested a second model that was the same as the first except that one subtest (making sets) was allowed to load not only on the contextual factor, but also on the action factor. The nature of this model is shown in Table 2. This model had a root mean square residual of 0.08 and fit the data well $\left[x^{2}(41, N=63)=42.83, p=\right.$ .39]. The improvement in fit over the first model was statistically significant $\left[x^{2}(1, N=63)=10.16, p<.005\right]$. The LISREL estimates of the loadings of the first-order factors on the second-order factor ranged from .66 to .89 .

With such a small sample size, it would be improper to give much weight to these tests of significance. However, we are inclined to accept the second model because it seems more justifiable theoretically. The task of making sets (unlike the other subtests) involves at least two types of counting knowledge-in particular, knowledge of the uses of counting and procedural knowledge involving the tagging of items in one-to-one correspondence with number words either during or after set formation.

The fit of the model proposed here was also tested against counting data independently collected in another project examining determinants of individual differences in young children's responsiveness to early mathematics instruction. A second-order maximum-likelihood confirmatory factor analysis was conducted using LISREL, in which an attempt was made to fit simultaneously the data sets from both experiments to the second model described above. This model fit the data well $\left[x^{2}(77, N s=63\right.$ and 37$)=64.37, p=$ .85 ]. The root mean square residual was 0.14 . (See Ferrara, 1987, for more details.)

\section{A Structural Model of Counting Competence}

In brief, the proposed model has three interactive components: verbal competence, action competence, and contextual competence. These three aspects of counting in their simplest form might be referred to as knowledge of (1) what one says, (2) what one does, and (3) when and why one speaks and acts in certain ways while counting.

The verbal component of counting includes both conceptual knowledge of the conventional number-word sequence 
and procedural knowledge for planning and executing production of the sequence or specific segments of that sequence (Fuson \& Hall, 1983; Fuson, Richards, \& Briars, 1982).

The action component of counting involves the performance aspects of object counting-specifically, the coordination of tagging behaviors with number words. Gelman (e.g., Gelman \& Gallistel, 1978) has claimed that a number of principles guide these behaviors, including the following: (1) the one-to-one principle that every object must be tagged with a unique number word, and (2) the orderirrelevance principle that the sequence in which objects in an array are tagged is unimportant. To execute properly these tagging behaviors, children must not only possess the conceptual knowledge just described, but also procedural knowledge for demonstrating these concepts. In particular, they must know how to keep track of which items have already been tagged.

Counting occurs in a variety of contexts, each with its own set of goals and necessary preconditions (Fuson \& Hall, 1983). The contextual component of counting includes conceptual knowledge of these contexts. Procedural knowledge associated with the contextual component involves methods for determining initially what context is relevant to the task and whether all necessary preconditions pertaining to that context have been met. It also involves methods for determining when the goal has been achieved. See Ferrara (1987) for further discussion of this model and a comparison of it to another model proposed by Greeno, Riley, and Gelman (1984).

\section{Implications for Development}

There is currently debate among researchers in this area regarding the existence of implicit principles that guide and constrain early development (as in the cognitive development literature in general). Most notably in the "principles" camp are Gelman and her associates (Gelman, 1980; Gelman \& Gallistel, 1978; Gelman \& Meck, 1983). Several other researchers, however, believe that the young child does not bring implicit principled knowledge to the acquisition of counting skills. Instead, it is claimed that counting and other numerical skills are rote learned by a process of imitation, associations, and so on (e.g., Fuson \& Hall, 1983; Siegler \& Shrager, 1984).

The present model of counting competence suggests a compromise position. Researchers in each camp have chosen to study phenomena that happen to support their positions. Those associated with the learning position have tended to study the development of number-sequence knowledge (Fuson \& Hall, 1983) and number facts in addition (Siegler \& Shrager, 1984). In the present model, this type of knowledge is associated with the verbal component exclusively. In contrast, Gelman and other proponents of the principles position have tended to emphasize the development of object-counting competence, with a focus on demonstration of one-to-one correspondence, cardinality, number-sequence stability, and irrelevance of tagging order. In the present model, these abilities load on the action and contextual factors only. Thus, it is possible that both views are partially correct and that a compromise position is most appropriate. Development of the verbal component of counting may be guided primarily by general principles of learning and a generalized tendency toward external consistency in the form of conventionalized behavior (Braine \& Rumain, 1983). However, development of the action and contextual components of counting may be guided by implicit domain-specific counting principles to which further knowledge will be assimilated.

\section{REFERENCES}

Baroody, A. J., \& Ginsburg, H. P. (1982). Preschoolers' informal mathematical skills. American Journal of Diseases of Children, 136, 195-197.

Baroody, A. J., \& Price, J. (1983). The development of the numberword sequence in the counting of three-year-olds. Journal for Research in Mathematics Education, 14, 361-368.

Braine, M. D. S., \& Rumain, B. (1983). Logical reasoning. In J. H. Flavell, \& E. M. Markman (Eds.), Handbook of child psychology: Vol. 3. Cognitive development (pp. 263-340). New York: Wiley.

Carpenter, T. P., \& Moser, J. M. (1982). The development of addition and subtraction problem-solving skills. In T. P. Carpenter, J. M. Moser, \& T. A. Romberg (Eds.), Addition and subtraction: A cognitive perspective (pp. 9-24). Hillsdale, NJ: Erlbaum.

FERRARA, R. A. (1987). Learning mathematics in the zone of proximal development: The importance of flexible use of knowledge. Doctoral dissertation, University of Illinois at Urbana-Champaign.

Fuson, K. C. (1982). An analysis of the counting-on solution procedure in addition. In T. P. Carpenter, J. M. Moser, \& T. A. Romberg (Eds.), Addition and subtraction: A cognitive perspective (pp. 67 81). Hillsdale, $\mathrm{NJ}$ : Erlbaum.

FusON, K. C., \& HALL, J. W. (1983). The acquisition of early number word meanings: A conceptual analysis and review. In H. P. Ginsburg (Ed.), The development of mathematical thinking (pp. 49-107). New York: Academic Press.

Fuson, K. C., Richards, J., \& Briars, D. J. (1982). The acquisition and elaboration of the number word sequence. In C. Brainerd (Ed.), Children's logical and mathematical cognition: Progress in cognitive development research (pp. 33-92). New York: Springer-Verlag.

Gelman, R. (1980). What young children know about numbers. Educational Psychologist, 15, 54-68.

Gelman, R., \& Gallistel, C. R. (1978). The child's understanding of number. Cambridge, MA: Harvard University Press.

Gelman, R., \& Meck, E. (1983). Preschooler's counting: Principles before skill. Cognition, 13, 343-359.

Greeno, J. G., Riley, M. S., \& Gelman, R. (1984). Conceptual competence and children's counting. Cognitive Psychology, 16, 94-143.

JöRESKOG, K. G., \& SöRbom, D. (1984). LISREL VI: Analysis of linear structural relationships by maximum likelihood, instrumental variables, and least squares methods (3rd ed.). Mooresville, IN: Scientific Software.

SiEgler, R. S., \& Robinson, M. (1982). The development of numerical understandings. In H. W. Reese \& L. P. Lipsitt (Eds.), Advances in child development and behavior (Vol. 16, pp. 241-312). New York: Academic Press.

Siegler, R. S., \& Shrager, J. (1984). Strategy choices in addition and subtraction: How do children know what to do? In C. Sophian (Ed.), Origins of cognitive skills: The 18th Annual Carnegie Symposium on Cognition (pp. 229-293). Hillsdale, NJ: Erlbaum.

(Manuscript received January 16, 1993.) 